\title{
Why Even Diminishing Principles of Entitlement Must Be Regulated by STRICTLY EgALITARIAN PRINCIPLES: DISCUSSION OF MORALITY OF FREEDOM
}

\author{
Michael Otsuka* \\ m.h.otsuka@Ise.ac.uk
}

1. Joseph Raz's novel, prescient, and richly multifaceted critique of egalitarianism builds on the notion of what he calls "ordinary" principles of entitlement to goods. He draws an exclusive distinction between such principles and those which he labels "strictly egalitarian". In the case of the latter, it "is the actually existing inequality of distribution which creates the entitlement. The entitlement is designed to eliminate a specific kind of existing inequality. Such principles reflect the view that it is wrong or unjust for some Fs to have G while others have not." By contrast, ordinary principles are "indifferent to the existing distribution of their benefits". If, for example, "the entitlement is based on need then each is entitled just to his needs. Unless the actual distribution of the benefit affects the nature or the extent of the need for it (which it may do) it is irrelevant to the right." $(226)^{1}$

The realization, however, of certain ordinary principles of entitlement, will tend, as a by-product, to increase the equality of a distribution. This holds for what Raz calls "satiable, diminishing principles of entitlement". A satiable principle is one whose "demands ... can be completely met" (235). A diminishing principle is one where "the more [of good] $G$ an $F$ has the weaker becomes the reason to give him more G" (236).

Raz defends the claim "that there is no case for relying on egalitarian principles in combination with diminishing principles" (239). This is because it would be superfluous or redundant to regulate an ordinary, diminishing principle of entitlement by a strictly egalitarian principle. Raz writes: "Strict egalitarian principles cannot be applied to diminishing principles of entitlement, which already have distributive commitments built into them". ${ }^{2}$ The fact that a tendency towards equality is already built into such a principle is meant to provide an explanation of why there is no case for applying strict egalitarian principles to diminishing principles of entitlement. ${ }^{3}$

\footnotetext{
* Professor of Philosophy, Department of Philosophy, Logic and Scientific Method, London School of Economics.

${ }^{1}$ All such page references are to JOSEPH RAZ, THE MORALITY OF FREEDOM (Oxford University Press, 1986). Most of them are to Ch. 9 on "Equality".

2 Oxford Scholarship Online abstract to Ch. 9.

${ }^{3}$ Raz elaborates on this point on pp. $239-40$, to which I shall return later.
} 
Only "non-diminishing and insatiable principles" of entitlement to goods "can be sensibly regulated by an egalitarian principle" (235). An "insatiable principle is one which it is always possible in principle to satisfy to a higher degree" (236). A non-diminishing principle is one where the strength of a reason to give a person a unit of some good $\mathrm{G}$ does not vary depending on how many units of $\mathrm{G}$ he already has.

Raz maintains that the "pursuit of pleasure is insatiable, and nondiminishing" (241). The classical utilitarianism's commitment to maximizing net pleasure therefore provides an example of a nondiminishing, insatiable principle. It follows that classical utilitarianism is indifferent to whether a unit of pleasure goes to someone who is very well off or very badly off. Hence "it tolerates extreme inequalities" (238). More generally, there is a prima facie case for the regulation of non-diminishing and insatiable principles by strictly egalitarian principles. This is because such principles, when unregulated, imply an intuitively unacceptable indifference to the increasing of great inequality.

Raz argues, however, that no sound principles of allocation are insatiable and non-diminishing: all such "insatiable non-diminishing principles are invalid" (p. 239) and any non-diminishing principle is "of doubtful significance to political morality". ${ }^{4}$ Rather, "any plausible principles of entitlement of a fundamental nature are satiable and diminishing" (241).

Hence, there is no case for strictly egalitarian principles.

2. In this paper, I shall argue that there is a sound case for the regulation of diminishing principles by strictly egalitarian principles.

I begin with some observations about what it is for a principle of entitlement to be diminishing. The quantity of one quality can be diminishing only in the quantity of another quality. If we're measuring only a single quality - such as the amplitude (i.e., the distance from resting point to peak) of a seismic wave - that quality can be neither increasing nor decreasing in itself. Of course, the Richter scale is logarithmic. It is therefore increasing in a linear scale. But there is still a single quality, a seismic wave, the measure of whose amplitude is neither increasing nor decreasing in itself. Rather, the same quality might be measured by different scales, the one scale (e.g., the logarithmic scale) of which might be increasing in the other scale (e.g., the linear scale). In order, therefore, for there to be a diminishing principle of entitlement to some good, there must be a quantity of some quality that diminishes in a quantity of some other quality, as measured by the same type (e.g., linear) of scale. We need an $x$-axis and a $y$-axis. We can't just have a $y$ axis, whose units might be either linear or logarithmic.

\footnotetext{
${ }^{4}$ Oxford Scholarship Online abstract to Ch. 9.
} 
Consider the diminishing marginal utility of money. Quantities of money are cardinally represented by a linear scale on the $x$-axis and quantities of happiness (i.e., utility) by a linear scale on the $y$-axis. The relation between the two is represented by a familiar-looking increasing, concavedownward-shaped curve. If one is a utilitarian of a fairly direct sort, then the strength of a person's entitlement to money will be represented by the utility-representing $y$-axis. This is because, for such a utilitarian, the strength of one's entitlement is simply the extent to which extra money enhances one's utility. Hence, the utilitarian's normative commitments transform the empirical fact of the diminishing marginal utility of money into a principle of entitlement.

For a utilitarian, therefore, a principle of entitlement to money will be a diminishing principle. As in the case of all diminishing principles, its fulfilment will give rise, as a by-product, to greater equality in the distribution of the good to which people are entitled. This is because a transfer of a unit of the good (i.e., a dollar) from someone who is better off to someone who is worse off, and who remains worse off even after the transfer, will always increase utility. It will also, as a by-product, decrease the inequality in the distribution between the pairs of people.

This example of a diminishing principle presents a challenge to Raz's claim that "there is no case for relying on egalitarian principles in combination with diminishing principles" (239). Raz maintains that there is no case because "diminishing principles lead to an approximately equal distribution in any case" (239). Hence, according to him, the regulation of a diminishing principle by a strictly egalitarian principle would "not affect the outcome" - it would not "affect the weight one would assign to different reasons, thus affecting the resulting distribution" (240). Raz expresses scepticism regarding the possibility that there is an "egalitarian principle at work" in regulating an ordinary diminishing principle of entitlement, where the existence of such an egalitarian principle "is merely masked by the fact that its results are the same as those of the underlying" ordinary diminishing entitlement principle. (239)

The example of a classical utilitarian principle of diminishing entitlement to money shows, however, that it is not necessarily redundant to regulate a diminishing principle of entitlement by a strictly egalitarian principle. This is for the reason that egalitarians would maintain that the reduction of inequality that occurs as a by-product of the maximization of utility does not deliver all the equality there ought to be. There is a call to equalize the circumstances of individuals above and beyond the equalization of the distribution of money that maximizes utility. Hence the regulation of the utilitarian principle of entitlement to money by a strictly egalitarian principle does not redundantly leave the resulting distribution unchanged. Rather, it makes a positive difference in the direction of greater equality. 
Raz in fact draws attention to the fact that it was a "reaction against the distributional consequences" of classical utilitarianism which "accounts for much of the appeal of strict egalitarianism. Those convinced of the soundness of classical utilitarianism in other respects felt that its one main failing is its disregard of the independent value of equality of net pleasure, and sought to supplement it with an egalitarian principle controlling the application of the basic utilitarian principle." (239)

One general lesson we can draw from this discussion is that an ordinary diminishing principle of entitlement to a good will not necessarily capture all of our convictions as to how much equality there should be. Among other reasons why this is so, a diminishing principle might not diminish at a fast enough rate to deliver, as a by-product, all the equality we think there should be. This can be illustrated by a diminishing principle that diminishes very, very slowly, and perhaps only across a certain range. Such a principle would introduce hardly any tendency towards equality. We can see now that what's key to Raz's redundancy critique of egalitarianism is the existence of sound diminishing principles where the diminution is of a sufficiently high rate, across a sufficiently large range.

3. From these observations, we can also show that the mere presence or absence of a point of satiation is not doing any direct work in Raz's argument against egalitarianism.

A non-diminishing, insatiable principle of entitlement can be represented by a graph with the $x$-axis representing quantities of the good on a linear scale and the $y$-axis the strength of one's entitlement to the good on a linear scale. The graphic representation would be by a straight, upwardly sloping line, which begins at the origin and infinitely extends upward and rightward. We can transform such a principle into a satiable principle simply by introducing a point very far along this straight line, where it abruptly kinks into a horizontal line that extends infinitely to the right. This would be the point of satiation. The insatiable, non-diminishing principle will have been transformed, by this kink, not only into a satiable principle, but also into one that is diminishing at some point. Satiation is, after all, formally speaking, just an instance of diminution down from a positive marginal benefit to a zero marginal benefit. A satiable principle must be diminishing, at least at the limit.

The introduction of a point of satiation, high up the line, wouldn't undermine the case for supplementation by an egalitarian principle. Suppose, for example, that a principle of entitlement to wealth is nondiminishing from zero dollars to a trillion dollar, at which point in the monetary stratosphere satiation is deemed to occur. Such a satiable principle would nevertheless have the same "unacceptable consequences" in tolerating "extreme inequalities" that Raz identifies (see 238) in an 
insatiable, non-diminishing principle of entitlement to wealth. Similarly, even if (contrary to Raz's belief) there were a high upper bound to pleasure, a point of satiation, classical utilitarianism would remain flawed below that bound, because it would remain indifferent to whether a unit of pleasure goes to someone below that boundary who has an enormous amount of pleasure or very little.

On the other hand a principle that was always diminishing at a high rate, even if insatiable, would exhibit a strong tendency to realize equality across the range of possible distributions. ${ }^{5}$ Raz's charge of the superfluousness of layering on of a distinct, strictly egalitarian principle would have prima facie plausibility even in the case of such an insatiable principle that diminishes at a high rate.

And, drawing on my earlier remarks, I would also maintain that, in the case of a principle that is diminishing and satiable, if the satiation is far enough distant, and the diminution is shallow enough, this would not be sufficient to establish even a prima facie case for the redundancy of its regulation by a strictly egalitarian principle.

4. The fact that there is a call for more equality than the utilitarian principle of diminishing entitlement to money yields does not necessarily establish that the utilitarian principle stands in need of regulation by a strictly egalitarian principle. The following different, non-egalitarian response to this defect of classical utilitarianism is both possible and credible. One might insist that we need to apply a further ordinary diminishing principle of entitlement to the principle of diminishing marginal utility of money. Our entitlement to utility itself is captured by an ordinary diminishing principle. This is the now familiar principle of prioritarianism, made famous by Derek Parfit. This move is in fact anticipated by Raz in the last section of his chapter on equality, where he argues that the "pursuit of happiness is diminishing and satiable" (241).

In order to represent such a diminishing principle, we transform the $x$ axis of the earlier graph so that it represents quantities of happiness (i.e. utility) rather than money. As before, the $y$-axis represents the strength of our entitlement to happiness. The relation between $x$-axis happiness and $y$-axis entitlement to happiness is captured, once again, by a familiar-looking increasing, concave-downward-shaped curve. This curve now serves to represent a prioritarian's commitment to the diminishing marginal value of utility rather than, as in the case of the earlier graph, the diminishing marginal utility of money.

\footnotetext{
${ }^{5}$ It should be noted that a prioritarian transformation of utility is typically represented as yielding an insatiable because always increasing as well as diminishing principle of entitlement. I shall say more about prioritarianism in the next section.
} 
If we plot a prioritarian principle of entitlement to money rather than utility, we will get an increasing, concave-downward-shaped curve that diminishes at a more rapid rate, since it will just be the further prioritarian concave transformation of the original concave curve that represents the diminishing marginal utility of money. On this graph, which combines the two previous graphs, the $x$-axis represents money and the $y$-axis represents prioritarian value.

In light of the existence of a prioritarian alternative to equality, Raz could qualify his critique of egalitarianism by resting it on the less sweeping claim that there always exists a sound, ordinary diminishing principle of entitlement that will render redundant or superfluous any egalitarian principle that one might try to apply to the distribution of the same goods. This claim might be true even if, as I have been arguing, not every sound, ordinary diminishing principle crowds out egalitarian principles that apply to the distribution of the same goods. This more modest claim, if true, would be sufficient to crowd out all egalitarian principles and therefore vindicate Raz's critique of egalitarianism.

One could, however, offer the following challenges to even this more modest claim. It remains open for an egalitarian to run the redundancy argument in the other direction. She could begin with the intuitive claim alluded to earlier that the principle of utility should be regulated by a strictly egalitarian principle. This is, for example, what Nagel proposed in his classic paper "Equality." Having done this, an egalitarian might then maintain that it would be redundant to introduce an ordinary, diminishing principle of entitlement to happiness, given that the non-diminishing utilitarian principle is already properly regulated by a strict egalitarian principle. Insofar as claims of redundancy are concerned, there appears to be a symmetry which creates a standoff between the egalitarian and the non-egalitarian. There is no obvious reason why the ordinary, diminishing principle must crowd out the egalitarian principle, rather than the other way around.

We can also press the following, more fundamental question: How does one justify the claim that there are any sound, ordinary diminishing principles of entitlement that compete with egalitarian principles in the first place? How, for example, does one establish the existence of a diminishing ordinary entitlement principle of happiness?

Raz offers the following suggestive remarks on behalf of the diminishing nature of happiness, which appeals to its satiability. He writes:

The satiability of the principle helps to explain why the pursuit of happiness is a diminishing principle. It indicates that the happier a person's life is the nearer it is to a state beyond which it cannot improve, at least not in happiness. That helps explain, we vaguely 
feel, why there is more reason to benefit those who are less happy than those who are more happy. In being further away from perfect happiness their lack is greater. (243)

Does, however, our entitlement always diminish as we get closer to the realizable ideal of a satiable principle? One can think of cases in which the increments that are closer to the ideal appear to take on a greater importance. Consider the final steps to the summit of Everest. Those might be of far greater importance than the initial steps from base camp. Suppose now that, in the case of happiness, satiation consists of the attainment of the extinction of desire and contented bliss of nirvana. As in the case of Everest, the last few steps on the path to enlightenment might be of greater importance than the earlier steps of a novice at meditation.

Given what I have just said, the case for diminution as one comes closer to the ideal might apply, not to satiable principles, but rather to insatiable principles of a particular sort: those which asymptotically converge on an upper bound, which might be understood as the ideal, which is never achievable. If further meditative steps were to take one closer and closer to nirvana, but one could never fully achieve, but only more closely approximate this state, the last steps might take on diminishing rather than increasing importance. This would be akin to a Mt. Everest to whose summit one could come closer and closer without ever reaching, as these steps have been etched into the stones by M. C. Escher.

5. There is the following further difficulty in establishing the existence of diminishing principles. In order to establish whether a principle of entitlement to a good is diminishing or non-diminishing, one must be able to identify units of the good, where the measure of the unit is independent of the strength of the reason we have to give someone the good. If we don't have such an independent measure, then we will lack a quantity of some quality that diminishes in the quantity of some other quality, which, as I mentioned earlier, is a presupposition of a diminishing principle of entitlement.

In the case of some goods, it is not difficult to identify such independently measurable units of the good. Money is perhaps the clearest example. The quantities of the unit of a dollar, for example, can simply be read off of the numbers printed on bank notes or statements. It is clear here that the measure of the unit is independent of the strength of the reason we have to give someone the good. A hundred dollar bill, for example, constitutes a hundred units of money, irrespective of to whomever it goes. Yet we have much stronger reason to give that bill to someone who is struggling to purchase groceries than to a billionaire.

In the central case under discussion in this paper of a principle of entitlement to happiness, however, it will be far more difficult to identify 
the unit in a manner that is independent of the strength of our entitlement to it. This is a point that John Broome has pressed against prioritarianism. He notes that prioritarianism depends on a "distinction between quantities of good and how much those quantities count", yet this distinction strikes him as "empty" where the good in question is wellbeing. ${ }^{6}$ This holds true whether or not we conceive of well-being as encompassing a complex notion of happiness, in a manner that coheres with Raz's views, or as consisting of net pleasure, as classical utilitarians believe.

Raz points to a diverse plurality of goods that typically constitute a person's well-being, when, for example, he writes: "Our notion of a successful life is of a life well spent, of a life of achievement, of handicaps overcome, talents wisely used, of good judgment in the conduct of one's affairs, of warm and trusting relations with family and friends, stormy and enthusiastic involvement with other people, many hours spent having fun in good company, and so on." (306)

But, as James Griffin has argued elsewhere, there is no pre-existing, preference-independent common measure of such a plurality of different goods that contribute to a person's well-being. ${ }^{7}$ Griffin maintains that, in the face of such pluralism, a person's rational and informed preferences regarding different ways her life might go will typically be "quantitatively basic: that is, they are judgments that do not depend upon other judgments about the amount of some quantity each option has". Rather, these preferences themselves form the "raw materials" out of which "the construction of a scale of measurement of well-being begins". ${ }^{8}$

Even if, rather than being pluralist about happiness, we are monist classical utilitarians of a Benthamite sort, according to which pleasure and the absence of pain are the only constituents of well-being, it remains unclear whether we can make sense of any independent units of amounts of pain or pleasure, to which to assign value that might diminish or increase.

Whether or not, therefore, we are pluralists or monists about well-being, it appears that we must rely on preferences, of an idealized sort, to provide the measure of well-being. ${ }^{9}$

\footnotetext{
6 JOHn BROOME, WeIGHING Goods (Blackwell, 1991), p. 217.

7 See James Griffin, Well-Being (Oxford University Press, 1986), pp. 30-31.

8 Ibid., p. 103.

${ }^{9}$ For further discussion and defence of the claims in this and the previous two paragraphs, see Michael Otsuka, Prioritarianism and the Measure of Utility, 23 JourNal OF PoliticAl PHILOSOPHY 1 (2015). Note that, as I mention there, a preference-based measure of utility does not imply the dubious claim that well-being is itself constituted by-or to be identified with the satisfaction of-preferences.
} 
I shall therefore assume a measure of utility on which a prospect has higher expected utility for a person just in case it would be preferred for her sake after rational and calm deliberation with all pertinent information while attending only to that which falls within the scope of her own interests (rather than falling solely within the scope of the interests of others). One prospect has the same expected utility as another for a person just in case such deliberation would yield indifference between the two prospects. In other words, I shall assume a measure of utility that is derived from idealized preferences satisfying the Von NeumannMorgenstern axioms. ${ }^{10}$

6. With this assumption in place, I am now in a position to offer the following reply to Raz's argument against egalitarianism. This reply is analogous to an argument on behalf of equality that Alex Voorhoeve and I have pressed against Parfit's prioritarianism. ${ }^{11}$ In a nutshell, the argument is as follows: a strict egalitarian principle can be justified as tracking the difference between intrapersonal and interpersonal trade-offs. It makes an important moral difference whether two different people have competing claims on goods, or whether two possible futures of a single person have competing claims on goods.

The argument can be illustrated in a manner that begins with a consideration of Thomas Nagel's well-known case involving the parent of two children. One of these children has recently been diagnosed with a condition that will soon give rise to a serious disability, but the other has been given a clean bill of health. You the parent need to choose whether to move your family to cramped urban accommodations or to the blue skies and open spaces of a semi-rural suburb. These two options would not be equally good for your two children. If you move to the city, your able-bodied child, who loves nature and sports, will be hemmed in and frustrated, but your (soon-to-be) disabled child will have access to special medical facilities. If you move to the suburb, your able-bodied child will flourish, but your disabled child will not receive this treatment. Moreover, if you move to the suburb, the boost in well-being to your able-bodied child will be slightly greater than the boost in well-being to your disabled child if you move to the city.

On Raz's view, one ought to move to the city, since well-being involves an ordinary diminishing principle of entitlement. By contrast, a utilitarian, for

\footnotetext{
${ }^{10}$ In this paragraph, I draw on Michael Otsuka and Alex Voorhoeve, Equality versus Priority, in OXFORD HANDBOOK OF DISTRIBUTIVE JUSTICE (Serena Olsaretti ed., forthcoming). ${ }^{11}$ In Michael Otsuka and Alex Voorhoeve, Why it Matters that Some are Worse Off than Others: An Argument Against the Priority View, 37 PHILOSOPHy \& PuBlic AfFaIRS 171, $177 n 14$ (2009), we maintain that "various other influential noncomparative, antiegalitarian views, such as those of Joseph Raz and Harry Frankfurt" are vulnerable to the critique that we press against Parfit's prioritarianism. In what follows, I try to make good on this claim.
} 
whom well-being is non-diminishing, would maintain that one ought to move to the suburb.

Now let us transform Nagel's two-child case into a case in which you have only a single child, who has an equal chance, so to speak, of turning out as either of Nagel's two children. In other words, suppose that you now have a single child, who has a $50 \%$ chance of developing the serious disability, and a $50 \%$ chance of being healthy. You must now decide whether to move to the city, where the child will receive special care if he turns out disabled, or to move to the suburb, where the child will flourish if he turns out healthy. As before, the benefit to the child of the suburb if healthy would be slightly greater than the benefit to him of the city if disabled.

I have argued that, in this one-child case, it is reasonable to maximize the child's expected utility. Hence it is permissible to move to the suburb. This is for the following reason:

Even if one maintains, as I do, that there are objective prudential goods, one should also maintain that ideally rational self-interested preferences will provide the measure of a person's well-being. Moreover, such preferences, being ideally rational, will conform to sound axioms of expected utility theory. It follows that ... you are permitted to maximize your child's expected utility in this one-child case on grounds that this is what it would be rational for him to prefer, taking all relevant normative considerations into account. ${ }^{12}$

In the two-child case, by contrast, one ought to move to the city. I maintain that:

This contrast, between the one-child and the two-child case, is explained by the fact that it matters whether or not there are others with competing claims to benefit. In the two-child case, one can ask the following rhetorical question: 'How can one justify providing a benefit of a given size to someone who is already better off in order to make him better off still, when one could instead provide nearly as large a benefit to someone else who is worse off, and who would not even reach the (unimproved) level of the better off person if she (the worse off person) is benefited?' An analogous complaint cannot be formulated against the maximization of expected utility in the one-child case. ${ }^{13}$

By contrast, someone such as Raz, who affirms the validity only of ordinary diminishing (and not also of strictly egalitarian) principles of entitlement, will be unable to distinguish the one-child from the two-child

12 Otsuka, "Prioritarianism and the Measure of Utility", supra note 10, at 5.

${ }^{13}$ Id. at $20 \mathrm{n} 55$. 
case in the manner I have described. ${ }^{14}$ Such an inability reveals an insensitivity to the moral significance of the separateness of persons. In Ch. 11 on "Consequentialism" of The Morality of Freedom, Raz attempts to defend consequentialists against this particular charge. He writes:

It is said that [consequentialism] equates a trade-off by giving a good to one person at the cost of depriving the same person of another good (e.g. he will get a refrigerator, but will lose his TV), with taking a good from one person in order to give it to another (taking one person's TV in order to give a refrigerator to another), without noticing that in the second case we trade across the boundaries between people. These boundaries, so the claim goes, drop out of the consequentialist reckoning. (272)

Raz offers the following response to this charge:

To this the consequentialist can reply with justice that the fact that trade-offs are between persons is taken into account. ...In comparing the value of a refrigerator and of a TV to one person one takes his situation into account. Hence the comparison is mindful of the fact that either way he will have something. When judging the value of the goods to two people one determines the value of each of the goods to each person in light of that person's general situation. In their case it is a choice between something and nothing, and this would affect the consequences of the reallocation to them. So the fact that the trade-off is across personal boundaries is reflected in the way that the value of the goods is judged in the second example. (ibid.)

Here Raz provides a sound response to the particular case under discussion, which involves intra-personal versus inter-personal trade-offs under conditions of certainty. Other cases can be constructed, however, which demonstrate the failure of consequentialism to properly distinguish intra-personal versus inter-personal trade-offs. My contrasting cases of two children, one unhealthy and the other healthy, whose fates are certain versus a single child who has a 50-50 chance of being unhealthy or healthy, provides just such a demonstration. This is because, unlike Raz's cases involving refrigerators and televisions, in my cases, the baselines from which benefits arise are equalized across the intrapersonal and the interpersonal scenarios. Moreover, as I have shown earlier, it is not just consequentialism, but also Raz's embrace of ordinary diminishing principles of entitlement alongside his rejection of strictly egalitarian principles, which can be shown by such a pair of cases to demonstrate inadequate regard for the moral significance of the separateness of persons.

${ }^{14}$ See id. at 1-22 for a further defence of this claim. 